\title{
CORRECTIONS
}

\section{Using economic evidence to support policy decisions to fund interventions for non-communicable diseases}

An editing error in this article by Melanie Bertram and colleagues (BMJ 2019;365:11648, 20 May; doi:10.1136/bmj.
11648) resulted in the lead author being attributed to the wrong department. She works for the Department of Health Systems Governance and Financing not the UN Inter-Agency Task Force on the Prevention and Control of NCDs. The job title of Nick Banatavala should also have been head of secretariat not team leader. Both errors have been corrected online. 